\title{
Cytotoxicity of various types of gold-mesoporous silica nanoparticles in human breast cancer cells
}

\author{
This article was published in the following Dove Press journal: \\ International Journal of Nanomedicine \\ 30 September 2015 \\ Number of times this article has been viewed
}

\author{
Guomu Liu',* \\ Qiongshu $\mathrm{Li}^{1}, 2, *$ \\ Weihua $\mathrm{Ni}^{1}$ \\ Nannan Zhang' \\ Xiao Zheng ${ }^{3}$ \\ Yingshuai Wang ${ }^{4}$ \\ Dan Shao ${ }^{3}$ \\ Guixiang Tai' \\ 'Department of Immunology, \\ College of Basic Medical Sciences, \\ Jilin University, Changchun, \\ ${ }^{2}$ Shenzhen Beike Cell Engineering \\ Research Institute, Yuanxing \\ Science and Technology Building, \\ Nanshan, Shenzhen, ${ }^{3}$ Department \\ of Pharmacology, Nanomedicine \\ Engineering Laboratory of Jilin \\ Province, College of Basic Medical \\ Sciences, ${ }^{4}$ State Key Laboratory on \\ Integrated Optoelectronics, College \\ of Electronic Science and Engineering, \\ Jilin University, Changchun, People's \\ Republic of China \\ *These authors contributed equally \\ to this work
}

\begin{abstract}
Recently, gold nanoparticles (AuNPs) have shown promising biological applications due to their unique electronic and optical properties. However, the potential toxicity of AuNPs remains a major hurdle that impedes their use in clinical settings. Mesoporous silica is very suitable for the use as a coating material for AuNPs and might not only reduce the cytotoxicity of cetyltrimethylammonium bromide-coated AuNPs but might also facilitate the loading and delivery of drugs. Herein, three types of rod-like gold-mesoporous silica nanoparticles (termed bare AuNPs, core-shell $\mathrm{Au} @ \mathrm{mSiO}_{2} \mathrm{NPs}$, and Janus $\mathrm{Au} @ \mathrm{mSiO}_{2} \mathrm{NPs}$ ) were specially designed, and the effects of these AuNPs on cellular uptake, toxic behavior, and mechanism were then systematically studied. Our results indicate that bare AuNPs exerted higher toxicity than the $\mathrm{Au} @ \mathrm{mSiO}_{2} \mathrm{NPs}$ and that Janus $\mathrm{Au} @ \mathrm{mSiO}_{2} \mathrm{NPs}$ exhibited the lowest toxicity in human breast cancer MCF-7 cells, consistent with the endocytosis capacity of the nanoparticles, which followed the order, bare AuNPs $>$ core-shell $\mathrm{Au} @ \mathrm{mSiO}_{2} \mathrm{NPs}^{>}>$Janus $\mathrm{Au} @ \mathrm{mSiO}_{2} \mathrm{NPs}_{\text {s }}$ More importantly, the AuNPs-induced apoptosis of MCF-7 cells exhibited features that were characteristic of intracellular reactive oxygen species (ROS) generation, activation of c-Jun-N-terminal kinase (JNK) phosphorylation, an enhanced Bax-to-Bcl-2 ratio, and loss of the mitochondrial membrane potential. Simultaneously, cytochrome c was released from mitochondria, and the caspase-3/9 cascade was activated. Moreover, both ROS scavenger ( $N$-acetylcysteine) and JNK inhibitor (SP600125) partly blocked the induction of apoptosis in all AuNPs-treated cells. Taken together, these findings suggest that all AuNPs induce apoptosis through the ROS-/JNK-mediated mitochondrial pathway. Thus, Janus $\mathrm{Au} @ \mathrm{mSiO}_{2} \mathrm{NPs}$ exhibit the potential for applications in biomedicine, thus aiding the clinical translation of AuNPs.
\end{abstract}

Keywords: gold nanoparticles, cytotoxicity, gold-mesoporous silica Janus nanoparticles, reactive oxygen species, c-Jun-N-terminal kinase, mitochondrial apoptosis

\section{Introduction}

Rapid advances in nanomedicine have generated an increasing number of potential diagnostic and therapeutic applications of nanoparticles in recent years. ${ }^{1-4}$ In particular, gold nanoparticles (AuNPs) have been widely used in industrial processes and commercial products and have seen major advances in their use for diagnostic and therapeutic purposes, including biosensor applications, the targeted delivery of anticancer drugs, bioimaging of cells and tissues, and immunoassays. ${ }^{5,6}$ However, obtaining knowledge about AuNPs and their health impact is essential before they can be used in clinical settings. The translation of AuNPs into the field of biomedicine is made difficult by several factors, one of the most important being the current incomplete knowledge regarding nano-bio interactions. ${ }^{7,8}$ Although AuNPs are considered inert and are regarded as biocompatible, contradictory results have been obtained concerning their toxicity. ${ }^{9,10} \mathrm{An}$ increasing number of scientific reports have been published addressing this issue, with the aim of understanding the effects of the size, shape, and surface functionalization of

submit your manuscript | www.dovepress.com 
AuNPs on cytotoxicity. ${ }^{11-13}$ Smaller particles exhibit greater surface area to volume ratios, thus providing a larger surface for interaction with cellular or intracellular components. ${ }^{14}$ As previous work has shown that classic AuNPs (15 nm) exhibit markedly lower cytotoxicity than atomic AuNPs (approximately 1-2 $\mathrm{nm}$ ) and that spherical AuNPs are generally more toxic than rod-like AuNPs and can cause irreversible structural changes that affect cell-cell contacts. ${ }^{15}$ Surface functionalization also affects the cytotoxicity of AuNPs. ${ }^{16}$ Cetyltrimethylammonium bromide (CTAB) is frequently applied, either during synthesis or to provide stability in physiological media, and can induce cell death independently of the AuNPs. ${ }^{17}$ The use of polymer or silica coatings can greatly reduce the toxic effects exhibited by AuNPs. ${ }^{18}$ Thus, studies to investigate the biological mechanisms of the toxicity caused by various AuNPs are urgently needed to fully determine the toxicological profile of AuNPs.

The toxic effects of AuNPs, including membrane injury, inflammatory responses, DNA damage, autophagy, and apoptosis in mammalian cells, have been demonstrated in a number of reports. ${ }^{19-21}$ These studies have also shown that the toxicity of AuNPs results from their particulate nature that can lead to the generation of reactive oxygen species (ROS). ${ }^{22}$ ROS are generated in all aerobic organisms and are indispensable for the signal transduction pathways that regulate cell growth and redox status. ${ }^{23}$ However, excess ROS generation is linked to DNA damage and cellular apoptosis and is known to activate mitogen-activated protein kinase (MAPK) pathways, which are important mediators of signal transduction that play a key role in regulating many cellular processes. ${ }^{24}$ MAPK pathways comprise three important components: extracellular-signal-regulating kinase (ERK1/2), stress-activated protein kinase/c-Jun$\mathrm{N}$-terminal kinase (JNK), and p38; these components are activated in response to oxidative stress. ${ }^{25} \mathrm{JNK}$ is induced by stress responses and cytokines, and has been identified as a direct activator of the mitochondrial death machinery, thereby providing a molecular linkage between oxidative stress and mitochondrial-mediated apoptosis. ${ }^{26}$ Typically, the mitochondrial membrane potential (MMP) is lost during mitochondrial-dependent apoptosis, and loss of MMP also induces apoptosis by causing the release of pro-apoptotic factors, such as cytochrome c (cyt c) and apoptosis-inducing factor, from the inner mitochondrial space to the cytosol. ${ }^{27}$ Cyt c released from mitochondria can activate caspase-9, which in turn activates executioner caspase-3 via cleavage induction. ${ }^{28}$ Although various reports have described the toxicity of AuNPs, the underlying molecular mechanism that leads to this toxicity remains largely unclear.
To increase the loading of drugs and reduce nanoparticle cytotoxicity, bare AuNPs have been coated with silica layers. ${ }^{29}$ In our previous work, we fabricated a theranostic system based on novel gold nanorod-mesoporous silica Janus nanoparticles (Janus $\mathrm{Au} @ \mathrm{mSiO}_{2} \mathrm{NPs}$ ) for combined photothermo-/chemo-cancer therapy. ${ }^{30}$ We observed that the cytotoxicity of bare AuNPs was much greater than that of the gold nanorod-mesoporous silica core-shell nanoparticles (core-shell $\mathrm{Au} @ \mathrm{mSiO}_{2} \mathrm{NPs}$ ) and Janus $\mathrm{Au} @$ $\mathrm{mSiO}_{2} \mathrm{NPs}$. More interestingly, our Janus $\mathrm{Au} @ \mathrm{mSiO}_{2} \mathrm{NPs}$ exhibited lower cytotoxicity than traditional core-shell Au@ $\mathrm{mSiO}_{2} \mathrm{NPs}$. However, details of the mechanisms underlying this unusual phenomenon remained lacking. Based on these studies, the goal of this work was to assess the cytotoxic potential of bare AuNPs, core-shell $\mathrm{Au} @ \mathrm{mSiO}_{2} \mathrm{NPs}$, and Janus $\mathrm{Au} @ \mathrm{mSiO}_{2} \mathrm{NPs}$ in human breast cancer cells (MCF-7) and to understand the molecular mechanisms involved. To achieve this goal, we systematically assessed cytotoxicity, ROS generation, the MMP, and apoptosis in relation to these three types of AuNPs. Levels of key signaling and apoptotic proteins along with the involvement of MAPK signaling pathways were analyzed. Moreover, both a ROS scavenger ( $N$-acetylcysteine [NAC]) and a JNK inhibitor (SP600125) were employed to demonstrate the role of the ROS/JNK-dependent mitochondrial pathway in the signaling of AuNPs-induced apoptosis.

\section{Materials and methods Reagents}

Sodium borohydride $\left(\mathrm{NaBH}_{4}\right), \mathrm{CTAB}$, tetraethyl orthosilicate (TEOS), ascorbic acid, silver nitrate and tetrachloroauric acid trihydrate $\left(\mathrm{HAuCl}_{4} \cdot 3 \mathrm{H}_{2} \mathrm{O}\right)$, 3-(4,5-dimethylthiazol-2yl)-2,5-diphenyltetrazolium bromide (MTT), NAC, and $2^{\prime} 7^{\prime}$ dichlorofluorescein diacetate (DCFH-DA) were obtained from Sigma-Aldrich Inc. (St Louis, MO, USA). Iscove's Modified Dulbecco's Medium and fetal bovine serum were obtained from Thermo Fisher Scientific (Waltham, MA, USA). All reagents were commercially available products of analytical grade purity and were used without further purification. A Bradford protein assay kit, radio immunoprecipitation assay lysis buffer, and an Annexin V-fluorescein isothiocyanate (FITC) apoptotic detection kit were obtained from the Beyotime Institute of Biotechnology (Jiangsu, People's Republic of China). Sodium dodecyl sulfate, tetramethylethylenediamine, glycine, ammonium persulfate, acrylamide, Tris, Tween-20, and proteinase inhibitors were purchased from Beijing Dingguo Biological Technology Co., Ltd (Beijing, People's Republic of China). All reagents were used without further purification. Deionized water was used in all experiments. The 
study was approved by the institutional review board (CWO) of College of Basic Medicine Science, Jilin University, PR China. No ethics committee permission was required for the use of human breast cancer cell line MCF-7 because only certificated cell lines provided by ATCC were used.

\section{Synthesis of bare AuNPs, core-shell Au@ $\mathrm{mSiO}_{2} \mathrm{NPs}$, and Janus $\mathrm{Au} @ \mathrm{mSiO}_{2} \mathrm{NPs}$}

The starting materials used to prepare the gold nanorods were prepared using a seed-mediated wet chemical approach and using $\mathrm{CTAB}$ as a surfactant. First, $7.5 \mathrm{~mL}$ of $\mathrm{CTAB}$ solution $(0.100 \mathrm{M})$ was mixed with $0.25 \mathrm{~mL} \mathrm{HAuCl}_{4}$ under stirring; then, $1.0 \mathrm{~mL}$ deionized water and $0.60 \mathrm{~mL}$ sodium borohydride $(0.010 \mathrm{M})$ was added, resulting in the formation of a brownish yellow solution. The solution was then stirred at $25^{\circ} \mathrm{C}$ for 2 hours. Then, $100 \mathrm{~mL}$ CTAB $(0.10 \mathrm{M})$ was added to $10 \mathrm{~mL}$ of $\mathrm{HAuCl}_{4}(0.001 \mathrm{M})$ solution, and 1 $\mathrm{mL}$ silver nitrate $(0.01 \mathrm{M})$ and $0.6 \mathrm{~mL}$ of $0.1 \mathrm{M}$ ascorbic acid were added after gentle mixing. After some time, the color of the growth solution changed from dark yellow to colorless. Finally, seed solution was added. The temperature of the growth medium was kept constant at $30^{\circ} \mathrm{C}$ for 6 hours to precipitate the AuNPs. The prepared AuNPs were washed with deionized water three times via centrifugation (10,000 rpm). Bare AuNPs were dispersed in $1 \mathrm{~mL}$ water after purification.

To obtain core-shell $\mathrm{Au} @ \mathrm{mSiO}_{2} \mathrm{NPs}$ (core-shell) of controlled aspect ratios, a modified sol-gel process was developed; TEOS was used as a silica source, CTAB was used as a template, and the AuNPs were used as a substrate. A solution of $0.8 \mathrm{mM} \mathrm{CTAB}$ was dispersed into $20 \mathrm{~mL}$ water and uniformly dispersed by ultrasonication for at least 40 minutes before clarification; AuNP solution was then added. The resulting dispersion was poured into a three-necked flask, and the temperature was maintained at $40^{\circ} \mathrm{C}$ under stirring. After 1 minute, $200 \mu \mathrm{L}$ of $0.1 \mathrm{M} \mathrm{NaOH}$ was rapidly added, and then a certain amount of $20 \%$ TEOS in methanol was added dropwise to the reaction for 48 hours at a speed of one drop per second. The core-shell $\mathrm{Au} @ \mathrm{mSiO}_{2} \mathrm{NPs}$ were recovered by centrifugation after briefly washing for five times with ethanol (5,000 rpm).

To obtain Janus $\mathrm{Au} @ \mathrm{mSiO}_{2} \mathrm{NPs}$ (Janus) of controlled aspect ratios, a modified sol-gel process was developed; TEOS was used as a silica source, CTAB was used as a template, and the AuNPs were used as a substrate. A solution of $50 \mathrm{mg}$ of CTAB was dispersed into $10 \mathrm{~mL}$ water and uniformly dispersed by ultrasonication for at least 40 minutes before clarification; AuNP solution was then added. The resulting dispersion was poured into a three-necked flask, and the temperature was maintained at $40^{\circ} \mathrm{C}$ under stirring. After 1 minute, $0.5 \mathrm{~mL}$ of ammonia water was rapidly added, and a certain amount of TEOS was then added dropwise into the reaction for 30 minutes at a certain speed. The Janus Au@, $\mathrm{mSiO}_{2} \mathrm{NPs}$ recovered by centrifugation after briefly washing five times with ethanol $(5,000 \mathrm{rpm})$. To extract CTAB from the NPs, as-synthesized product was dispersed in the ethanol solution of $\mathrm{NH}_{4} \mathrm{NO}_{3}(60 \mathrm{~mL}, 10 \mathrm{mg} / \mathrm{mL})$. The mixture was refluxed for 6 hours and washed with ethanol three times and dispersed in $5 \mathrm{~mL}$ of anhydrous ethanol for further use.

\section{Characterization}

Transmission electron microscopy (TEM) images of bare AuNPs, core-shell Au@mSiO ${ }_{2} \mathrm{NPs}$, and Janus $\mathrm{Au} @$ $\mathrm{mSiO}_{2} \mathrm{NPs}$ were obtained using a Hitachi model H-7650 TEM (Hitachi Ltd., Tokyo, Japan) operated at $100 \mathrm{kV}$. UV-Vis-NIR spectra were obtained using a Tecan Infinite M200 spectrophotometer. Zeta-potential measurements of the nanoparticles were obtained using a Malvern Zeta sizer Nano ZS instrument.

\section{Cell culture and cellular uptake}

Cells of the human breast cancer cell line MCF-7 were cultured in Iscove's Modified Dulbecco's Medium, 10\% fetal bovine serum, $100 \mathrm{U} / \mathrm{mL}$ penicillin, and $100 \mu \mathrm{g} / \mathrm{mL}$ streptomycin at $37^{\circ} \mathrm{C}$ under $5 \% \mathrm{CO}_{2}$. MCF-7 cells were seeded on lean coverslips in a 24 -well plate at a seeding density of $2 \times 10^{4}$ cells per well. After 24 hours, the medium was discarded. Then, fresh culture without serum and antibiotics was added. To measure the intracellular localization of the AuNPs, FITC-labeled NPs were co-cultured with MCF-7 cells for 3 hours. Then, the cells were washed twice with chilled phosphate-buffered saline (PBS), and the nuclei were stained using Hoechst 33258 dye $(5 \mathrm{mg} / \mathrm{mL})$ for 5 minutes. The location of the NPs was observed using an Olympus FV1000 confocal laser scanning microscope equipped with multi-line argon LASER $(405,488 \mathrm{~nm})$ and a $30 \mathrm{~mW}$ Laser class 3D laser.

\section{Cytotoxicity assessment}

The in vitro cytotoxicity of bare AuNPs, core-shell Au@ $\mathrm{mSiO}_{2} \mathrm{NPs}$, and Janus $\mathrm{Au} @ \mathrm{mSiO}_{2} \mathrm{NPs}$ against MCF-7 cells was assessed at various time points using an MTT cell viability assay. In brief, cells were seeded in 96-well plates at a density of $1 \times 10^{4}$ cells per well overnight and then treated with various concentrations $(200,100,50,25$, $12.5,6.25,3.13$, and $1.56 \mu \mathrm{g} / \mathrm{mL}$ ) of each NP for 24,48 , or 72 hours. The absorbance at $570 \mathrm{~nm}$ was measured using a microplate reader (BioTek Instruments, Inc., Winooski, VT, 
USA). Relative cell viability was calculated as A570 nm (AuNP-treated cells at Tn)/A570 nm (control at Tn) $\times 100 \%$ (VT, USA) based on three independent experiments.

\section{Annexin V-FITC/propidium iodide apoptosis assay}

To investigate the effect of bare AuNPs, core-shell Au@ $\mathrm{mSiO}_{2} \mathrm{NPs}$, and Janus $\mathrm{Au} @ \mathrm{mSiO}_{2} \mathrm{NPs}$ on apoptosis, MCF-7 cells were placed in a six-well culture plate at a density of $5 \times 10^{5}$ cells per well and treated with $12.5 \mu \mathrm{g} / \mathrm{mL}$ of each NPs or with NPs plus NAC/SP600125 for 24 hours. Normal, apoptotic, and necrotic cells were distinguished using an Annexin V-FITC/propidium iodide assay kit according to the manufacturer's instructions. Then, cells were washed with PBS, resuspended in $500 \mu \mathrm{L}$ of binding buffer, and $1 \mu \mathrm{L}$ of AnnexinV-FITC was added to the samples. After incubation for 5 minutes at $4^{\circ} \mathrm{C}$ in the dark, $1 \mu \mathrm{L}$ of propidium iodide was added, and the mixture was incubated for 5 minutes at $4{ }^{\circ} \mathrm{C}$. Flow cytometry analysis was performed within 15 minutes.

\section{Assessment of the MMP}

The MMP was monitored using the mitochondrial permeability lipophilic JC-1 fluorescence dye according to the manufacturer's instructions. MCF-7 cells were placed in a six-well culture plate at a density of $5 \times 10^{5}$ cells per well and treated with $12.5 \mu \mathrm{g} / \mathrm{mL}$ of each NP for 24 hours. The cells were then incubated for 20 minutes at $37^{\circ} \mathrm{C}$ in $1 \mathrm{~mL}$ of culture medium containing JC-1. The cells were then rinsed twice with ice-cold JC-1 staining buffer and subsequently analyzed using flow cytometry.

\section{Measurement of ROS generation}

Intracellular ROS production was measured using the oxidation-sensitive fluorescence probe DCFH-DA (Sigma, Shanghai, People's Republic of China). After treatment with $12.5 \mu \mathrm{g} / \mathrm{mL}$ of each NP or with NPs plus NAC for 24 hours, the cells were washed twice with PBS and then loaded with DCFH-DA in serum-free medium and incubated at $37^{\circ} \mathrm{C}$ for 20 minutes. ROS production by the MCF-7 cells was evaluated using both an inverted fluorescence microscope (IX71; Olympus Corporation, Tokyo, Japan) and a FACScan flow cytometer (BD Biosciences, San Jose, CA, USA).

\section{Western blotting analysis}

MCF-7 cells were placed in a six-well culture plate at a density of $5 \times 10^{5}$ cells per well and treated with $12.5 \mu \mathrm{g} / \mathrm{mL}$ of each NP or with NPs plus NAC/SP600125 for 24 hours. Then, the cells were lysed using radio immunoprecipitation assay lysis buffer, and the protein concentrations of the cell lysates were measured using a bicinchoninic acid protein assay kit (Beyotime Biotechnology, Jiangsu, People's Republic of China). Equal amounts of cell lysate protein were resolved in $12 \%$ sodium dodecyl sulfate-PAGE gels and transferred to polyvinylidene difluoride membranes (EMD Millipore, Billerica, MA, USA). Primary antibodies against the following proteins were used: JNK (Cell Signaling Technology, Danvers, MA, USA), p-JNK (Cell Signaling Technology), ERK (Cell Signaling Technology), p-ERK (Cell Signaling Technology), p38 (Cell Signaling Technology), p-p38 (Cell Signaling Technology), Bax (Proteintech, Chicago, IL, USA), Bcl-2 (Epitomics, Burlingame, CA, USA), cytochrome-c (Epitomics), caspase-3 (Epitomics), caspase-9 (Epitomics), PARP (Epitomics) and GAPDH (Proteintech).

\section{Results}

\section{Characterization and cellular uptake of the three AuNPs}

Bare AuNPs, core-shell Au@mSiO ${ }_{2} \mathrm{NPs}$, and Janus Au@ $\mathrm{mSiO}_{2} \mathrm{NPs}_{\mathrm{s}}$ were synthesized as previously reported, and the AuNPs were characterized as shown in Figure 1. TEM confirmed that all AuNPs exhibited uniform rod-like structures; three cylinders with increased dimensions of 40-60/10-20 nm
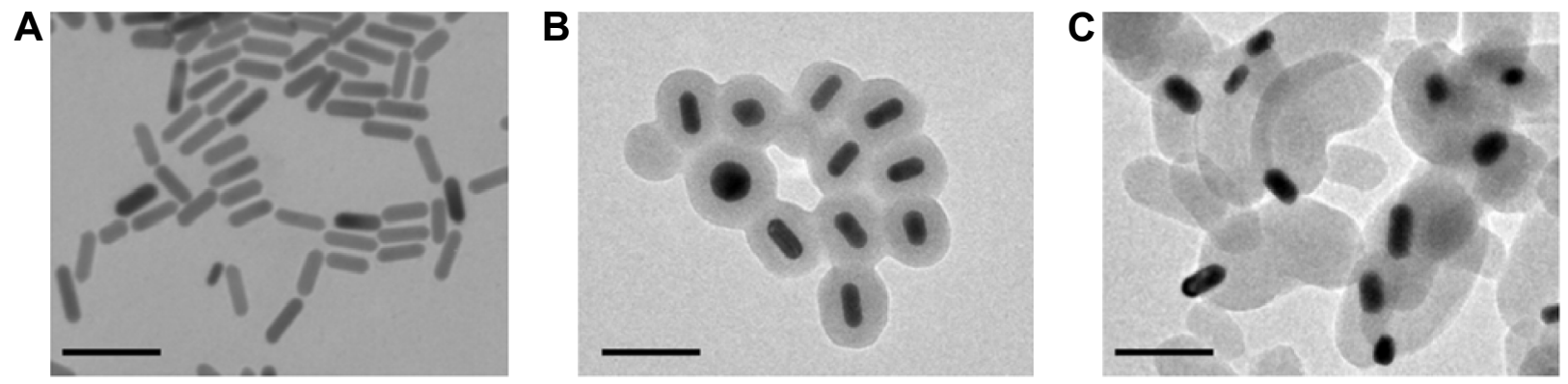

Figure I Characterization of three rod-like gold-mesoporous silica nanoparticles.

Notes: TEM images showing bare AuNPs (A), core-shell Au@mSiO ${ }_{2} N_{s}(\mathbf{B})$, and janus Au@mSiO 2 NPs (C). The scale bar represents 200 nm.

Abbreviations: AuNPs, gold nanoparticles; TEM, transmission electron microscopy. 
(AuNPs), 80-100/40-60 nm (core-shell Au@mSiO ${ }_{2} \mathrm{NPs}$ ), and 200-300/100-150 nm (Janus Au@mSiO_NPs) were obtained. As reported in our previous study, ${ }^{30}$ the three types of AuNP all exhibited a similar transverse surface plasmon resonance (TSPR) band, located at approximately $530 \mathrm{~nm}$; compared with the longitudinal surface plasmon resonance (LSPR) band obtained for bare AuNPs at $600 \mathrm{~nm}$, the coreshell Au@mSiO $\mathrm{mPs}_{2}$ were red-shifted by almost $110 \mathrm{~nm}$ (approximately $70 \mathrm{~nm}$ higher than Janus $\mathrm{Au} @ \mathrm{mSiO}_{2} \mathrm{NPs}$ ). Moreover, bare AuNPs and core-shell Au@mSiO $\mathrm{NPs}$ exhibited positive zeta potentials of $+34.2 \mathrm{mV}$ and $+14.7 \mathrm{mV}$, respectively, whereas Janus $\mathrm{Au} @ \mathrm{mSiO}_{2} \mathrm{NP}$ exhibited a neutral zeta potential of $+2.1 \mathrm{mV}$ in deionized water. To explore the localization of the three types of AuNPs in human breast cancer MCF-7 cells, the nanoparticles were labeled using the fluorescence marker FITC, and confocal microscopy was used to monitor the cellular uptake of the FITC-labeled AuNPs. As shown in Figure 2, all AuNPs were taken up by the cells and were mainly located in the cytoplasm and in the perinuclear region. More importantly, the highest cellular uptake was exhibited by the AuNPs, whereas the core-shell
$\mathrm{Au} @ \mathrm{mSiO}_{2} \mathrm{NPs}$ were more easily internalized by cells than the Janus $\mathrm{Au} @ \mathrm{mSiO}_{2} \mathrm{NPs}$.

\section{Mitochondrial apoptotic pathway induction by the three types of AuNPs}

The cytotoxicity of three types of AuNPs to MCF-7 cells was assessed using the MTT assay, and the results are shown in Figure 3A and B. MCF-7 cells that were exposed to each of the AuNPs for 24 hours at dose levels of $1.5625-200 \mu \mathrm{g} / \mathrm{mL}$ showed significantly decreased cell viability, and this decrease was concentration-dependent. More importantly, bare AuNPs and core-shell $\mathrm{Au} @ \mathrm{mSiO}_{2} \mathrm{NPs}_{\mathrm{S}}$ exhibited much greater cytotoxicity than Janus $\mathrm{Au} @ \mathrm{mSiO}_{2} \mathrm{NPs}$; all AuNPs showed less cytotoxicity at concentrations of less than $6.25 \mu \mathrm{g} / \mathrm{mL}$. Thus, we examined the time-dependent toxicity of AuNPs at $12.5 \mu \mathrm{g} / \mathrm{mL}$. As shown in Figure 3B, the viability of MCF-7 cells after exposure to each of the AuNPs at $12.5 \mu \mathrm{g} / \mathrm{mL}$ decreased dramatically with time. Compared with coreshell Au@mSiO 2 NPs, Janus Au@mSiO $2 \mathrm{NPs}_{2}$ consistently exhibited lower cytotoxicity; $\mathrm{Au} @ \mathrm{mSiO}_{2} \mathrm{NPs}$ consistently exhibited higher cytotoxicity than other $\mathrm{Au} @ \mathrm{mSiO}_{2} \mathrm{NPs}$ at

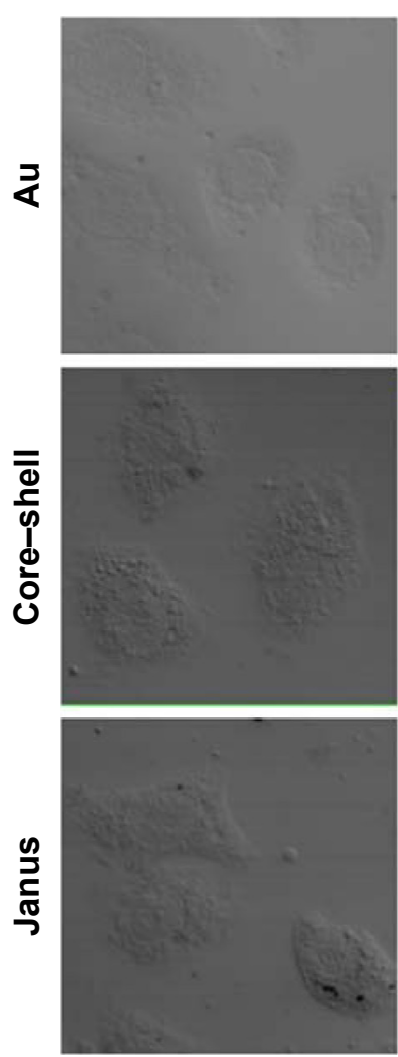

Bright-field
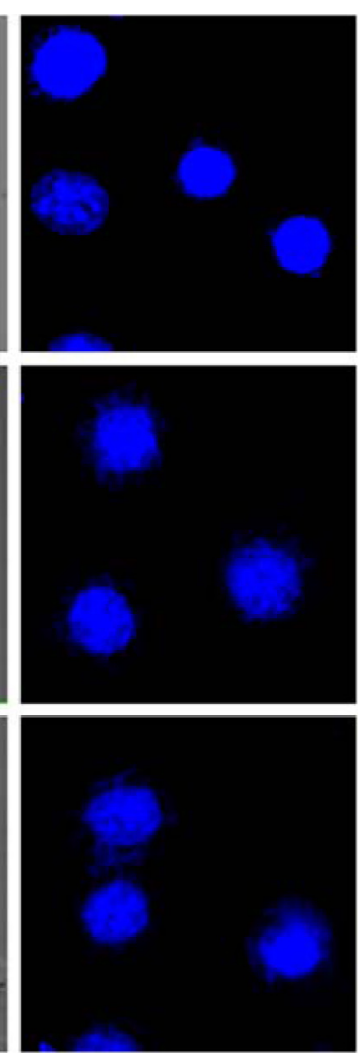

Hoechst
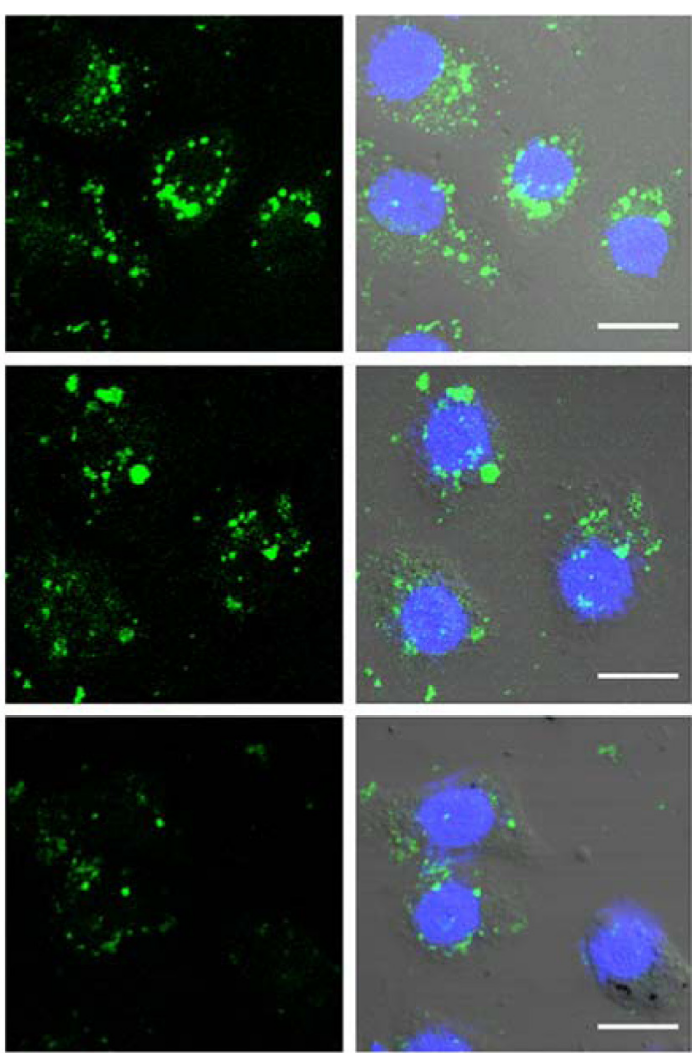

FITC

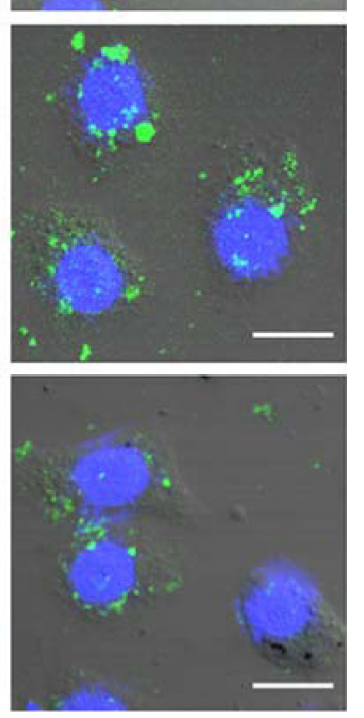

Overlay

Figure 2 Endocytosis of three rod-like gold-mesoporous silica nanoparticles.

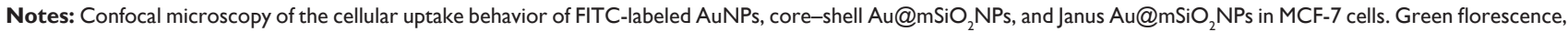
FITC; blue florescence, nuclei stained with Hoechst 33258. Scale bars represent $10 \mu \mathrm{m}$.

Abbreviations: AuNPs, gold nanoparticles; FITC, fluorescein isothiocyanate. 
A

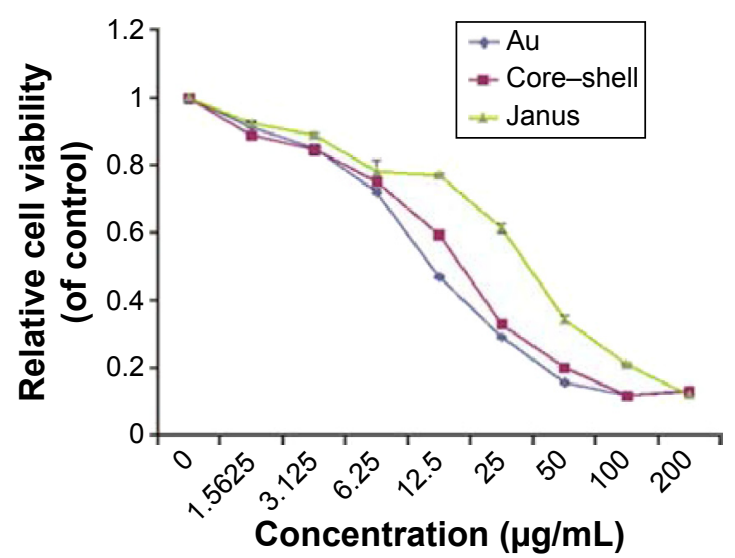

C

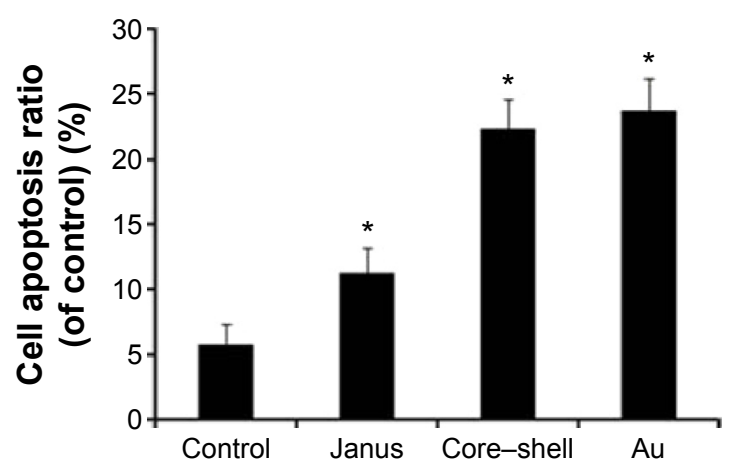

B
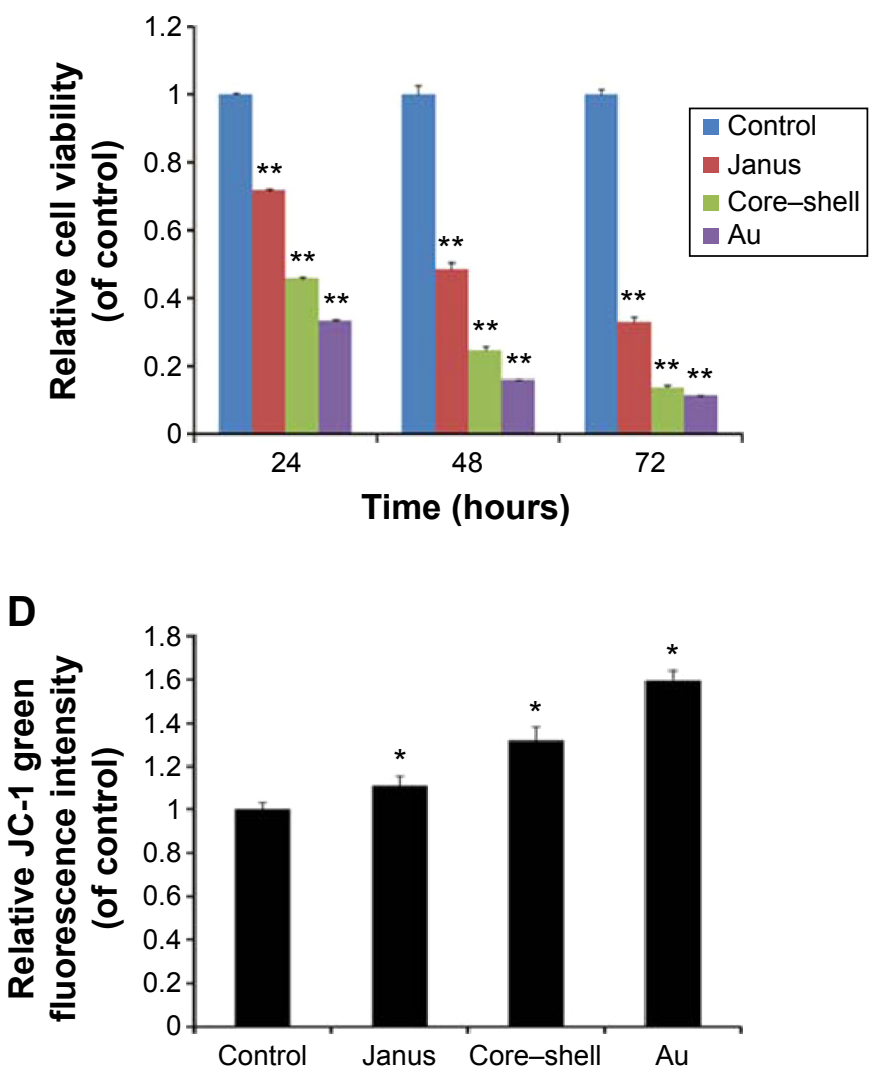

Figure 3 Mitochondrial apoptosis induced by three rod-like gold-mesoporous silica nanoparticles.

Notes: (A) MTT assay showing MCF-7 cells after incubation with three rod-like gold-mesoporous silica nanoparticles at various concentrations (I.56-200 $\mu$ g/mL) for 24 hours. (B) MTT assay showing MCF-7 cells after separate incubation with $12.5 \mu \mathrm{g} / \mathrm{mL}$ of three rod-like gold-mesoporous silica nanoparticles for various time intervals (24, 48, or 72 hours). (C) MCF-7 cells were treated separately with $12.5 \mu \mathrm{g} / \mathrm{mL}$ of three rod-like gold-mesoporous silica nanoparticles for 24 hours; the apoptotic ratio was then assessed by Annexin V-FITC/PI binding and measured using flow cytometry. (D) Changes in the MMP were detected using JC-I staining and analyzed by flow cytometry. The data represent three separate experiments. Mean values $\pm S D$. $* P<0.05$ versus a control group, $* * P<0.01$ versus a control group.

Abbreviations: Au, gold; FITC, fluorescein isothiocyanate; PI, propidium iodide; MTT, 3-(4,5-dimethylthiazol-2-yl)-2,5-diphenyltetrazolium bromide.

each time point. To investigate whether the cytotoxicity of the AuNPs at 24 hours was caused by apoptosis in MCF-7 cells, the number of apoptotic cells was measured using Annexin V-FITC/PI staining after treatment with $12.5 \mu \mathrm{g} /$ $\mathrm{mL}$ of each of the three AuNPs for 24 hours. As shown in Figure 3C, 5.8\% of the cells were apoptotic in the control group; after treatment with bare AuNPs, core-shell Au@, $\mathrm{mSiO}_{2} \mathrm{NPs}$, and Janus $\mathrm{Au} @ \mathrm{mSiO}_{2} \mathrm{NPs}$, the percentages of apoptotic cells were $11.3 \%, 22.3 \%$, and $23.7 \%$, respectively. Compared with the control, each of the three AuNPs triggered marked apoptosis in MCF-7 cells; Janus $\mathrm{Au} @ \mathrm{mSiO}_{2} \mathrm{NPs}$ caused fewer cells to undergo apoptosis, whereas the bare AuNPs caused more cells to undergo apoptosis. To assess the role of mitochondria in AuNP-induced cell apoptotic death, we tested whether each AuNP caused a loss of the MMP by staining with the fluorescent probe JC-1 at 24 hours. As shown in Figure 3D, all AuNPs caused an obvious decrease in the MMP in MCF-7 cells, and the results were consistent with above cytotoxicity and apoptosis measurements. These results indicate that all AuNPs-induced apoptosis through the mitochondrial pathway.

\section{ROS generation and MAPK activation during AuNP-induced apoptosis}

The generation of intracellular ROS is always associated with MMP disruption and cell apoptosis. To investigate the upstream regulatory mechanisms leading to AuNPsinduced mitochondrial dysfunction, we analyzed changes of intracellular ROS in MCF-7 cells using fluorescence microscopy and flow cytometry. As shown in Figure 4A, all AuNPs-induced ROS generation after 24 hours of exposure in MCF-7 cells, as indicated by the increased fluorescence intensity (Figure 4B). The highest amount of ROS was generated by the bare AuNPs treatment, and the least amount was generated by the Janus $\mathrm{Au} @ \mathrm{mSiO}_{2} \mathrm{NPs}$ treatment. It is clear that ROS can lead to the activation of MAPKs and 


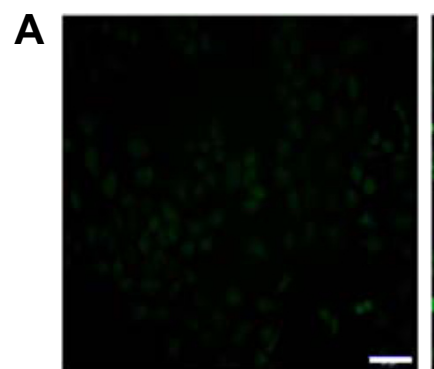

Control

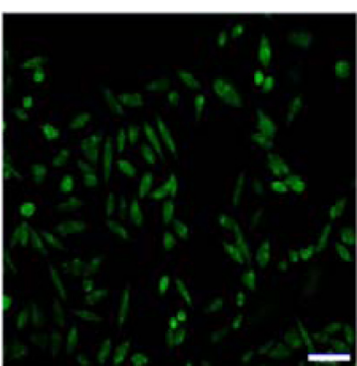

Janus AuNPs

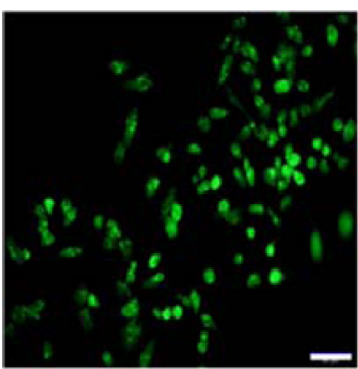

Core-shell AuNPs

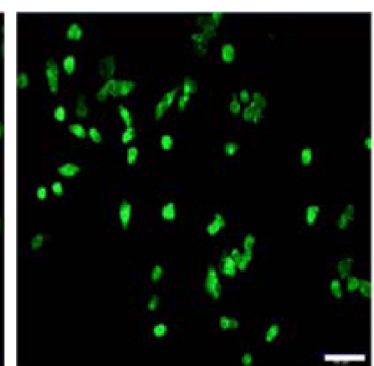

AuNPs

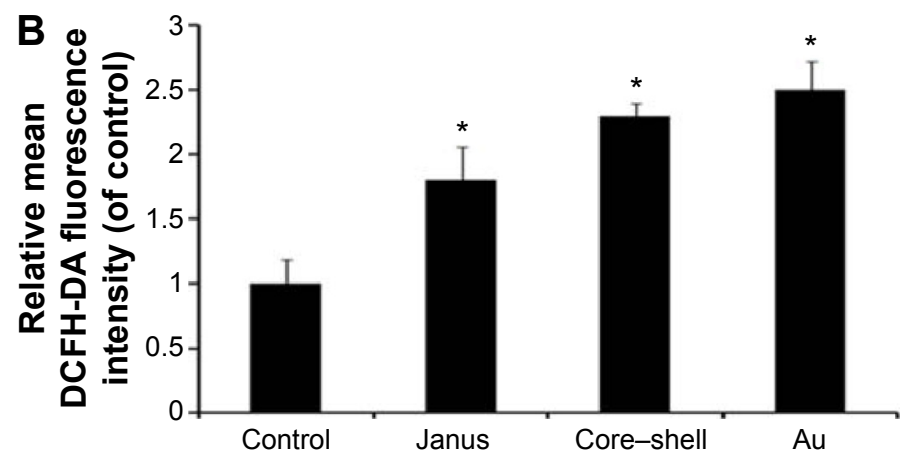

Figure 4 ROS generation induced by three rod-like gold-mesoporous silica nanoparticles.

Notes: MCF-7 cells were separately treated with $12.5 \mu \mathrm{g} / \mathrm{mL}$ of three rod-like gold-mesoporous silica nanoparticles for 24 hours; then, intracellular ROS were stained using DCFH-DA and measured using fluorescence microscopy (A) and flow cytometry (B). The scale bars represent $50 \mu \mathrm{m}$. The data represent three separate experiments. Mean values \pm SD. $* P<0.05$ versus a control group.

Abbreviations: AuNPs, gold nanoparticles; ROS, reactive oxygen species; DCFH-DA, 2'7'-dichlorofluorescein diacetate; SD, standard deviation.

thereby induce apoptosis; therefore, we next examined the effect of AuNPs on the MAPK signal pathway by evaluating the phosphorylation states of JNK, p38, and ERK through western blotting analysis. As shown in Figure 5A, JNK phosphorylation was gradually increased after treatment with each of the AuNPs, but ERK1/2 phosphorylation was significantly reduced. Moreover, bare AuNPs exhibited greater effects than the other $\mathrm{Au} @ \mathrm{mSiO}_{2} \mathrm{NPs}$; core-shell $\mathrm{Au} @ \mathrm{mSiO}_{2} \mathrm{NPs}$ exhibited a greater effect than Janus $\mathrm{Au} @$ $\mathrm{mSiO}_{2} \mathrm{NPs}$. Interestingly, p38 phosphorylation was almost affected in each of the AuNP-treated MCF-7 cells. Because Bcl-2 family members play a vital role in the regulation of the mitochondrial apoptotic pathway, the levels of Bax and Bcl-2 were measured by western blotting analysis. As shown in Figure 5B and C, all AuNP treatments suppressed Bcl-2 expression and upregulated Bax expression compared to untreated cells; this result was most vividly illustrated by a marked increase in the Bax/Bcl-2 expression ratio. Treatment with bare AuNPs resulted in a higher Bax/Bcl-2 expression ratio than treatment with other $\mathrm{Au} @ \mathrm{mSiO}_{2} \mathrm{NPs}$, and treatment with Janus $\mathrm{Au} @ \mathrm{mSiO}_{2} \mathrm{NPs}$ resulted in the lowest Bax $/ \mathrm{Bcl}-2$ expression ratio. The release of cyt $\mathrm{c}$ from mitochondria can activate the caspase cascade. Members of the caspase family are related to cysteine proteases and act as effectors of the apoptotic process downstream of both the death receptor and mitochondrial apoptotic pathways. Thus, we investigated the involvement of cyt c, caspase-9, caspase-3, and PARP in this process using western blotting analysis. Moreover, treatment with the bare AuNPs caused the greatest release of cyt $\mathrm{c}$ in the cytosolic fraction, the greatest activation of caspase- 9 and caspase- 3 , and the greatest cleavage of PARP; in contrast, treatment with the Janus $\mathrm{Au} @ \mathrm{mSiO}_{2} \mathrm{NPs}$ caused the least release of cyt $\mathrm{c}$ in the cytosolic fraction, the least activation of caspase- 9 and caspase- 3 , and the least cleavage of PARP.

\section{Role of ROS and JNK in AuNP-induced apoptosis}

To further determine whether ROS participates in AuNPinduced apoptosis, we pre-treated MCF-7 cells with $5 \mathrm{mM}$ NAC, a ROS scavenger that does not affect cell proliferation. We observed that NAC abrogated the cytotoxicity of each of the AuNPs and markedly changed the proportion of apoptotic cells to $8.5 \%, 11.2 \%$, and $13.2 \%$, respectively (Figure 6A and B). As expected, the presence of NAC significantly reduced the accumulation of intracellular ROS that was induced by each of the three AuNPs (Figure 6C). Furthermore, the activation of JNK in cells that had been 
A

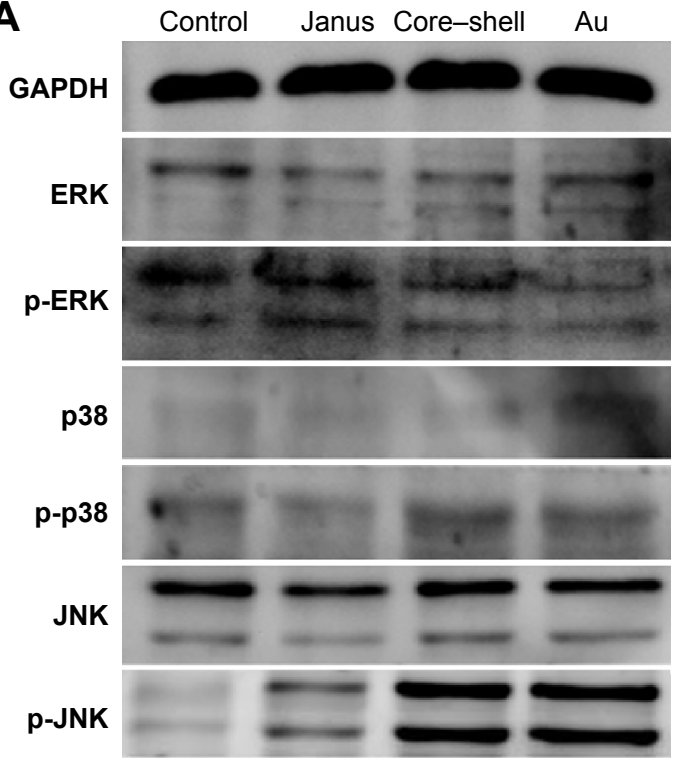

C

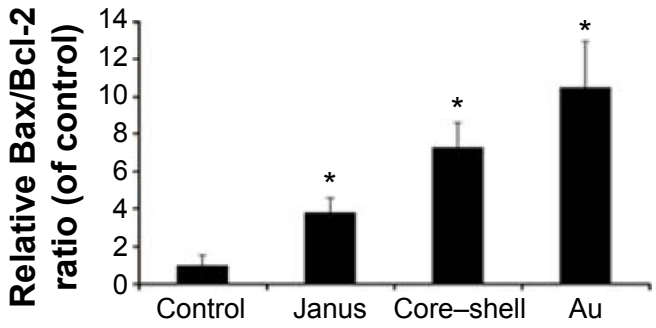

B

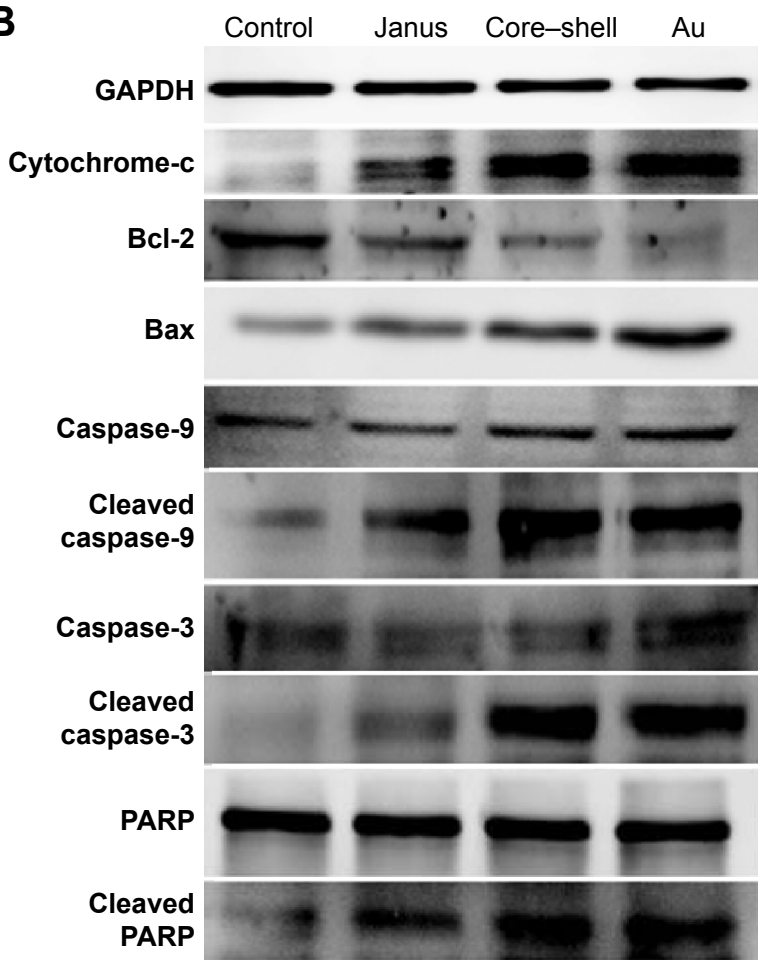

Figure 5 Roles played by MAPK subfamilies in the mitochondrial apoptosis induced by three rod-like gold-mesoporous silica nanoparticles.

Notes: MCF-7 cells were separately treated with $12.5 \mu \mathrm{g} / \mathrm{mL}$ of three rod-like gold-mesoporous silica nanoparticles for 24 hours; then, whole-cell lysates were collected and immunoblotted using antibodies against MAPK subfamily proteins, such as ERK, p-ERK, p38, p-p38, JNK, and p-JNK (A), as well as apoptosis-related proteins, such as cyt c, $\mathrm{Bcl}-2$, Bax, caspase-9, caspase-3, and PARP (B). GAPDH was used as a standard to ensure the equal loading of lysates. (C) Quantitative analysis of the ratio of Bax/Bcl-2. Values are presented as means \pm SD of three determinations. ${ }^{*} P<0.05$ versus control group.

Abbreviations: Au, gold; MAPK, mitogen-activated protein kinase; ERK, extracellular-signal-regulating kinase; JNK, c-Jun-N-terminal kinase; cyt c, cytochrome c; Bcl-2, B-cell lymphoma-2; Bax, Bcl-2-associated X protein; PARP, polyADP-ribose polymerase; GAPDH, glyceraldehyde-3-phosphate dehydrogenase; SD, standard deviation.

treated with each of the AuNPs could partly be abolished by NAC. Furthermore, NAC blocked the activation of caspase-3 that was induced by each of the AuNPs (Figure 6D). To further analyze whether JNK activation plays a role in AuNP-induced apoptosis, the effects of the JNK inhibitor SP600125 (30 $\mu \mathrm{M})$ on cell death were examined. As shown in Figure 7A and B, SP600125 treatment significantly blocked the increases in cytotoxicity and apoptosis that were induced by each of the AuNPs. In addition, SP600125 remarkably suppressed the JNK phosphorylation and caspase- 3 activation that was induced by each of the AuNPs (Figure 7C). These results indicate that each of the AuNPs-induced apoptosis through a ROS/JNK-mediated mitochondrial pathway.

\section{Discussion}

AuNPs with nonporous structures exhibit low loading capacities and limited elasticity, thus restricting their application in effective drug delivery. ${ }^{6,31}$ Therefore, the development of multifunctional gold-based nanomaterials that not only exhibit less cytotoxicity than CTAB-coated AuNPs but also deliver both drugs and heat, is highly desired. Mesoporous silica is very suitable for use as a coating material for AuNPs. Such coated particles would have great potential for biomedical applications as delivery agents for anticancer drugs, DNA, and proteins due to their large surface area, tunable size, high accessible pore volume, and well-defined surface properties. ${ }^{32}$ Various simple and robust methods have been reported for the synthesis of multifunctional mesoporous silica-encapsulated AuNPs (core-shell Au@mSiO $2 \mathrm{NPs}_{2}$ ) for use as cancer theranostics. ${ }^{33,34}$ Previously, we successfully designed and synthesized Janus $\mathrm{Au} @ \mathrm{mSiO}_{2} \mathrm{NPs}_{\text {, which }}$ might not only efficiently deliver imaging agents or drugs into cancer cells but also exhibit good photothermal properties, thus representing a promising theranostic candidate for use in combined photothermo-/chemo-cancer therapy..$^{30}$ Given 


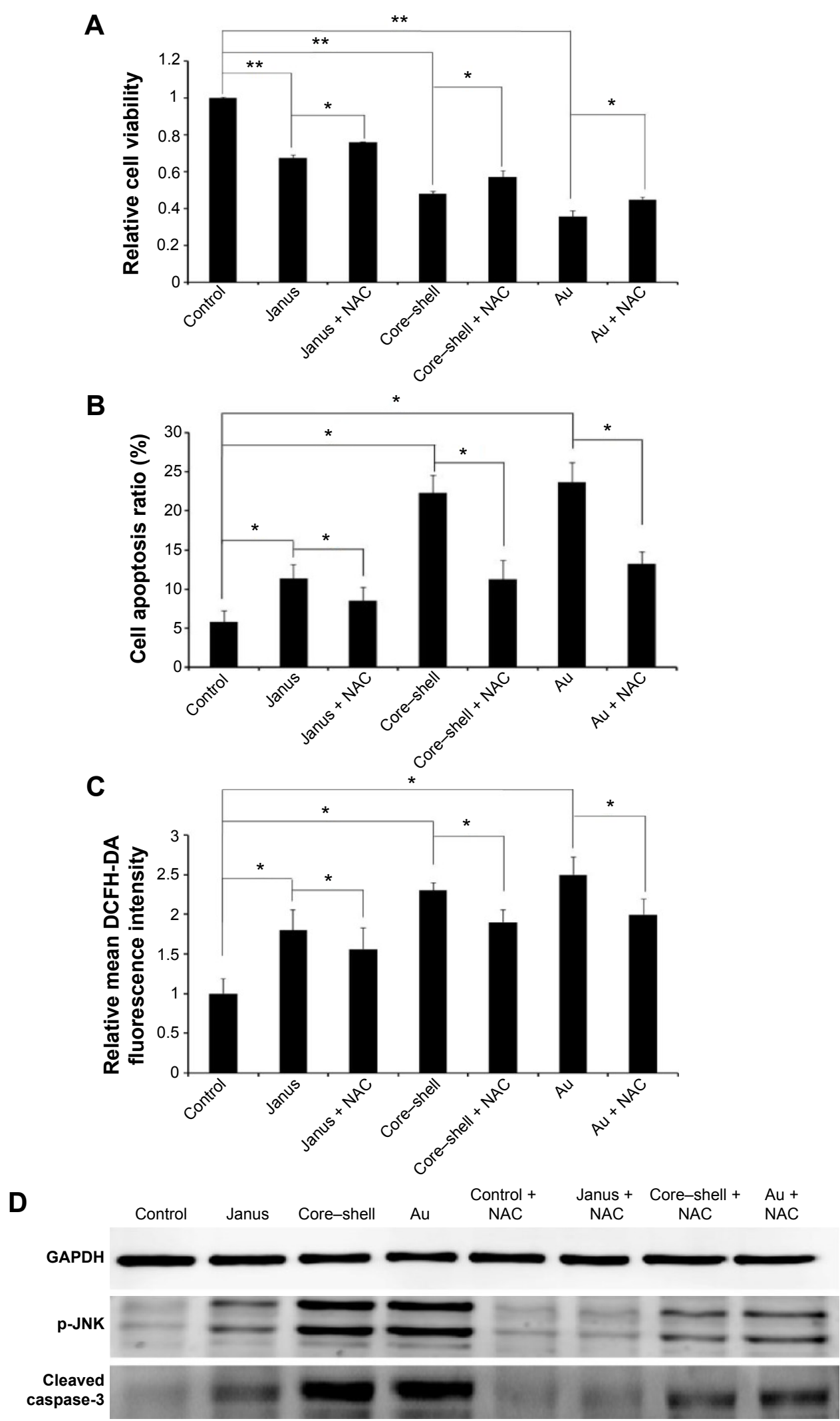

Figure 6 The effect of ROS on the mitochondrial apoptosis induced by three rod-like gold-mesoporous silica nanoparticles.

Notes: MCF-7 cells were separately treated with $12.5 \mu \mathrm{g} / \mathrm{mL}$ of three rod-like gold-mesoporous silica nanoparticles for 24 hours in the presence or absence of $5 \mathrm{mM}$ NAC. (A) Cytotoxicity was analyzed using an MTT assay. (B) The apoptotic ratio was assessed based on Annexin V-FITC/PI binding and measured using flow cytometry analysis. (C) Intracellular ROS were stained using DCFH-DA and measured using flow cytometry. (D) The expression of p-JNK and cleaved caspase-3 was analyzed using western blotting. The data represent three separate experiments. Mean values $\pm S D$. $* P<0.05$ versus a control group, $* * P<0.01$ versus a control group.

Abbreviations: Au, gold; DCFH-DA, 2'7'-dichlorofluorescein diacetate; ROS, reactive oxygen species; FITC, fluorescein isothiocyanate; Pl, propidium iodide; MTT, 3-(4,5dimethylthiazol-2-yl)-2,5-diphenyltetrazolium bromide; NAC, N-acetylcysteine; JNK, c-Jun-N-terminal kinase; SD, standard deviation. 

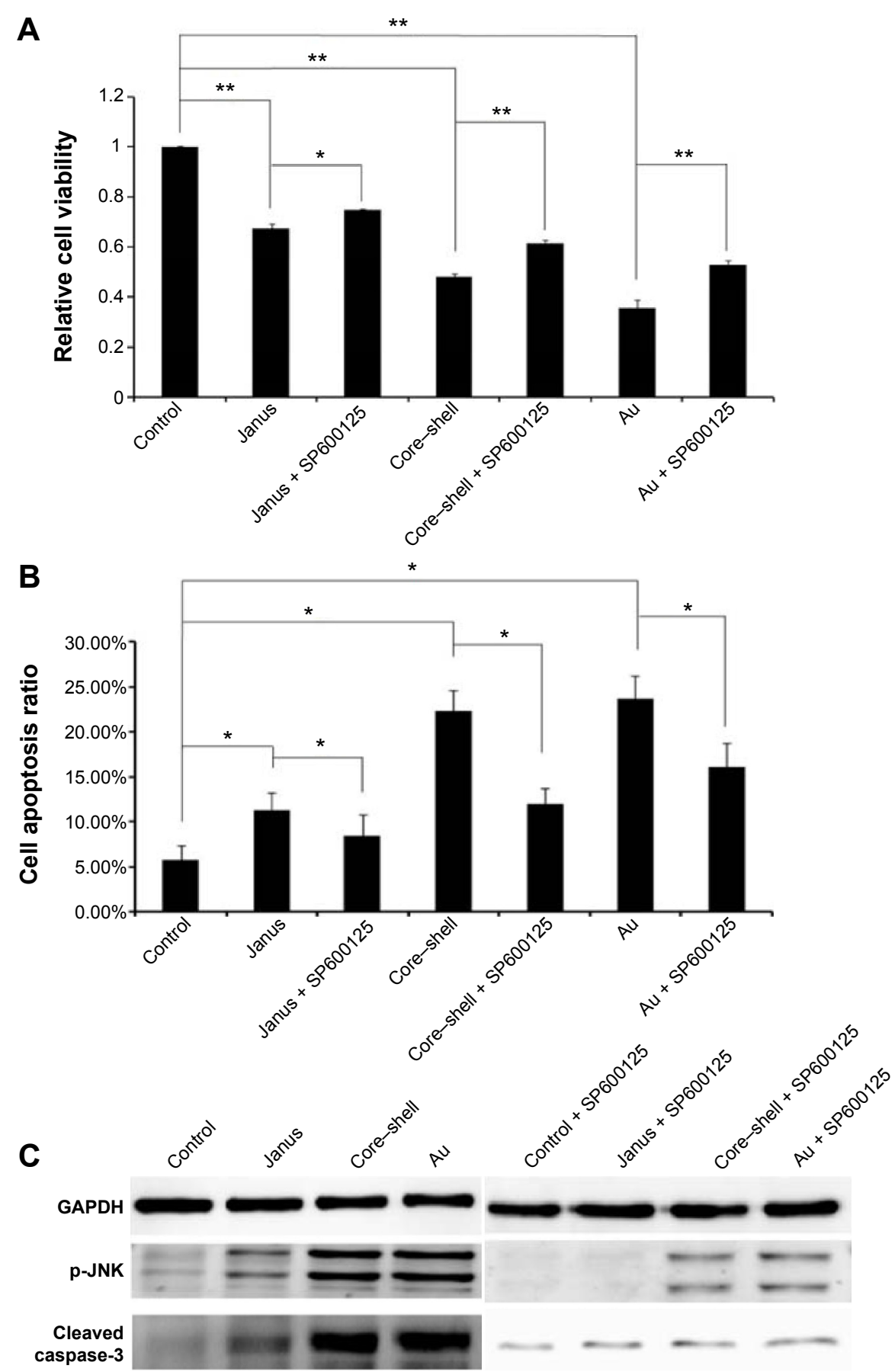

Figure 7 The effect of JNK on the mitochondrial apoptosis induced by three rod-like gold-mesoporous silica nanoparticles.

Notes: MCF-7 cells were separately treated with $12.5 \mu \mathrm{g} / \mathrm{mL}$ of three rod-like gold-mesoporous silica nanoparticles for 24 hours in the presence or absence of $30 \mu \mathrm{M}$ SP600125. (A) Cytotoxicity was analyzed using an MTT assay. (B) Then, the apoptotic ratio was assessed based on Annexin V-FITC/PI binding and measured using flow cytometry. (C) The expression of $\mathrm{p}-\mathrm{JNK}$ and cleaved caspase- 3 was analyzed using western blotting. The data represent three separate experiments. Mean values \pm SD. $* P<0.05$ versus a control group, $* * P<0.01$ versus a control group.

Abbreviations: Au, gold; FITC, fluorescein isothiocyanate; GAPDH, glyceraldehyde-3-phosphate dehydrogenase; PI, propidium iodide; MTT, 3-(4,5-dimethylthiazol-2-yl)2,5-diphenyltetrazolium bromide; SP600 I25, I,9-pyrazoloanthrone; JNK, c-Jun-N-terminal kinase; SD, standard deviation.

their dramatically increasing applications in biomedicine, AuNPs should be studied to ensure their in vitro and in vivo biocompatibility and biosafety. However, no studies have yet compared the cytotoxicity of bare AuNPs, core-shell $\mathrm{Au} @ \mathrm{mSiO}_{2} \mathrm{NPs}$, and Janus $\mathrm{Au} @ \mathrm{mSiO}_{2} \mathrm{NPs}$; thus, it is not possible to draw general conclusions about the mechanisms underlying the effects of unmodified AuNPs.

The present study reveals the effects of three types of AuNPs on human breast cancer cells and provides significant insight into the possible mechanism through which they 
exert their toxic effects on these cells. We fabricated three rod-like AuNPs and characterized these uniform AuNPs using TEM, spectrophotometry, and Zeta potentiometry. We found that bare AuNPs exhibited the smallest size and most positive charge, whereas Janus $\mathrm{Au} @ \mathrm{mSiO}_{2} \mathrm{NPs}$ exhibited the largest size and the most negative charge; these interesting characteristics represent key factors for affecting endocytosis and cytotoxicity. Subsequently, we investigated the endocytosis of the three types of AuNPs. It was clear from our results (Figure 2) that the internalization of the AuNPs by MCF-7 cells appears to depend on particle size; the smallest (bare) AuNPs were more easily internalized by cells than the larger $\mathrm{Au} @ \mathrm{mSiO}_{2} \mathrm{NPs}$, a finding that is consistent with several previous studies. ${ }^{35}$ A probable reason for this phenomenon is that small nanoparticles exhibit a greater ability to be taken up into cells; 40 and $50 \mathrm{~nm}$ nanoparticles induced the greatest cellular effect, and positive nanoparticles evoked a greater response than neutral or negative nanoparticles due to their stronger interaction with the negatively charged cell membrane. ${ }^{35}$ Data obtained using an in vitro MTT assay showed that three types of AuNPs-induced marked growth inhibition of MCF-7 cells at concentrations of greater than $12.5 \mu \mathrm{g}$ / $\mathrm{mL}$ and that the strength of the antiproliferative effect followed the order, bare AuNPs $>$ core-shell Au@mSiO $\mathrm{NPs}_{2}$ $>$ JanusAu@mSiO ${ }_{2}$ NPs. This behavior might be explained by considering that AuNPs are more easily taken up via cell endocytosis than other $\mathrm{Au} @ \mathrm{mSiO}_{2} \mathrm{NPs}$ or by considering that mesoporous silica coatings largely prevent the release of toxic CTAB from the surface of AuNPs.

Oxidative stress is the most discussed paradigm for the toxicity of NPs. This has been attributed to their small size, because large surface area is generally thought to produce ROS and oxidative stress. ${ }^{36,37}$ Three AuNPs in our study were found to be capable of generating intracellular ROS when stained with the cell permeable dye DCFH-DA, and the ROS inhibitor NAC significantly reduced ROS production and apoptosis induced by the AuNPs, suggesting that ROS generation plays a key role in the AuNP-induced apoptosis of MCF-7 cells. This observation is consistent with earlier studies, which showed similar effects on PC12 and C17.2 cells in a dose- and time-dependent manner. ${ }^{38}$ Due to the lower intracellular amount of the particles and the fast time required for AuNPs-treated cell liberated ROS, 24 hours is commonly considered the optimal time to assess the effect of NP exposure on ROS levels; therefore, we investigated ROS triggered AuNPs-induced apoptosis in MCF-7 cells using 24 hours as our experimental exposure time.
Mitochondria play a pivotal role in the signal transduction of apoptosis. It is also known that increased concentrations of ROS and the consequent loss of the MMP are characteristic of mitochondria-dependent apoptosis. ${ }^{39}$ In our study, we found that the apoptosis induced by each of the AuNPs was initiated by the generation of ROS, followed by a loss of the MMP and the release of cyt c into the cytosol, leading to activation of the caspase-9/-3 cascade; these events were blocked by NAC. These results demonstrated that apoptosis was induced by each of the AuNPs through ROS-mediated activation of the mitochondrial apoptotic pathway. Moreover, ROS signaling appeared to be triggered by the activation of the mitochondrial-dependent cell death pathway through the activation of MAPK pathways.

Cellular redox state and cellular signaling are closely related. MAPKs, including JNK, ERK, and p38, are mediators of the cellular response to extracellular signals. ${ }^{40}$ The elucidation of MAPK signaling during apoptotic processes might explain the effects of ROS action. ${ }^{41} \mathrm{JNK}$ and p38 MAPKs are induced by stress responses and are closely associated with cell death. ${ }^{42}$ In contrast, ERK is generally associated with proliferation and growth. ${ }^{43}$ Here, we showed that treatment with each of the AuNPs resulted in a marked activation of JNK and the inactivation of ERK; however, only bare AuNPs significantly increased the phosphorylation of $\mathrm{p} 38$. Differences in the curvature of the different types of AuNPs and the release of $\mathrm{CTAB}$ in the cell, thereby inducing the activation of $\mathrm{p} 38 \mathrm{might}$ explain this phenomenon. In addition, JNK activation was partly prevented in the presence of NAC, suggesting that the AuNPs-induced JNK through a ROS-dependent mechanism. To decipher the link between ROS and JNK in AuNP-induced toxicity in MCF-7 cells, cells were treated with AuNPs in the presence of the specific inhibitor SP600125. Importantly, we found that inhibition of the JNK pathway by SP600125 protected the cells from apoptosis. These results showed that JNK kinases play a key role in AuNP-induced apoptosis. However, the activation of JNK kinases by AuNP-generated ROS might represent an adaptive response to bypass stress injury. Taken together, these results indicate that ROS-evoked JNK activation might trigger the mitochondrial-dependent cell death pathway based on the well-established role of these kinases in ROS-mediated apoptosis.

Based on the above results, we hypothesize that the interaction between AuNPs and cells occurs through the following chain of events: endocytosis of the AuNPs, alteration of oxidative stress, and changes in mitochondrial behavior, finally resulting in altered cell proliferation and apoptosis. In contrast to the numerous studies regarding the effect of many types of 
AuNPs on cell function, few reports have compared the effect of bare AuNPs, core-shell Au@mSiO ${ }_{2} \mathrm{NPs}$, and Janus $\mathrm{Au} @$ $\mathrm{mSiO}_{2} \mathrm{NPs}_{\mathrm{s}}$ on endocytosis and cytotoxicity. The major finding of this study was that different types of AuNPs can be internalized in cells through nonspecific cellular uptake, resulting in ROS-induced JNK activation and subsequently triggering the mitochondrial-dependent cell death pathway. These findings provide insights that might prove helpful for the development of strategies to design safe and efficient drug delivery nanocarriers and for understanding the environmental fate of AuNPs.

\section{Conclusion}

Here, we demonstrated that three well-defined AuNPs in the 50-300 nm size range exhibited clear time- and dose-dependent toxicity in human breast cancer MCF-7 cells. Bare AuNPs exerted greater toxicity than the tested $\mathrm{Au} @ \mathrm{mSiO}_{2} \mathrm{NPs}$ due to their higher endocytosis capacity in MCF-7 cells. Moreover, ROS-mediated oxidative stress, JNK activation, upregulation of the $\mathrm{Bax} / \mathrm{Bcl}-2$ ratio, loss of the MMP, cyt c release into the cytosol, and activation of the caspase-9/-3 cascade were involved in the mitochondrial-dependent apoptosis pathways induced by each of the AuNPs. Taken together, these findings show that AuNPs alternatively induce antiproliferation effects in MCF-7 cells and that AuNPs-induced apoptosis is mediated through a ROS/JNK-dependent mitochondrial/ caspase pathway. Based on these results, it can be concluded that Janus Au@mSiO_NPs exhibited less toxicity than bare AuNPs or core-shell Au@mSiO ${ }_{2}$ NPs. Thus, the interplay between cell responses and particle shape will undoubtedly be important for the investigation of numerous areas of interest, including the design of safe gold-based nanoplatforms that can translate to clinical use and the shaping of subsequent regulation policies.

\section{Acknowledgment}

This study was supported by the research funds from the Frontier Interdiscipline Program of Norman Bethune Health Science Center of Jilin University (No 2013101001).

\section{Disclosure}

The authors report no conflicts of interest in this work.

\section{References}

1. Muthu MS, Mei L, Feng SS. Nanotheranostics: advanced nanomedicine for the integration of diagnosis and therapy. Nanomedicine (Lond). 2014;9(9):1277-1280.

2. Shao D, Zeng Q, Fan Z, et al. Monitoring HSV-TK/ganciclovir cancer suicide gene therapy using $\mathrm{CdTe} / \mathrm{CdS}$ core/shell quantum dots. Biomaterials. 2012;33(17):4336-4344.
3. Shao D, Li J, Xiao X, et al. Real-time visualizing and tracing of HSV-TK/GCV suicide gene therapy by near-infrared fluorescent quantum dots. ACS Appl Mater Interfaces. 2014;6(14):11082-11090.

4. Shao D, Li J, Pan Y, et al. Noninvasive theranostic imaging of HSV-TK/ GCV suicide gene therapy in liver cancer by folate-targeted quantum dot-based liposomes. Biomater Sci. 2015;3(6):833-841.

5. Jans H, Huo Q. Gold nanoparticle-enabled biological and chemical detection and analysis. Chem Soc Rev. 2012;41(7):2849-2866.

6. Dykman L, Khlebtsov N. Gold nanoparticles in biomedical applications: recent advances and perspectives. Chem Soc Rev. 2012;41(6): 2256-2282.

7. Alkilany AM, Lohse SE, Murphy CJ. The gold standard: gold nanoparticle libraries to understand the nano-bio interface. Acc Chem Res. 2013;46(3):650-661.

8. Cao-Milan R, Liz-Marzan LM. Gold nanoparticle conjugates: recent advances toward clinical applications. Expert Opin Drug Deliv. 2014; 11(5):741-752.

9. Alkilany AM, Murphy CJ. Toxicity and cellular uptake of gold nanoparticles: what we have learned so far? J Nanopart Res. 2010;12(7): 2313-2333.

10. Dreaden EC, Alkilany AM, Huang X, Murphy CJ, El-Sayed MA. The golden age: gold nanoparticles for biomedicine. Chem Soc Rev. 2012; 41(7):2740-2779.

11. Pan Y, Neuss S, Leifert A, et al. Size-dependent cytotoxicity of gold nanoparticles. Small. 2007;3(11):1941-1949.

12. Jain PK, Lee KS, El-Sayed IH, El-Sayed MA. Calculated absorption and scattering properties of gold nanoparticles of different size, shape, and composition: applications in biological imaging and biomedicine. J Phys Chem B. 2006;110(14):7238-7248.

13. Schaeublin NM, Braydich-Stolle LK, Schrand AM, et al. Surface charge of gold nanoparticles mediates mechanism of toxicity. Nanoscale. 2011; 3(2):410-420.

14. Jahnen-Dechent W, Simon U. Function follows form: shape complementarity and nanoparticle toxicity. Nanomedicine (Lond). 2008;3(5): 601-603.

15. Coradeghini R, Gioria S, Garcia CP, et al. Size-dependent toxicity and cell interaction mechanisms of gold nanoparticles on mouse fibroblasts. Toxicol Lett. 2013;217(3):205-216.

16. Hauck TS, Ghazani AA, Chan WC. Assessing the effect of surface chemistry on gold nanorod uptake, toxicity, and gene expression in mammalian cells. Small. 2008;4(1):153-159.

17. Yah CS. The toxicity of gold nanoparticles in relation to their physiochemical properties. Biomed Res. 2013;24(3):400-413.

18. Shi XY, Wang SH, Sun HP, Baker JR. Improved biocompatibility of surface functionalized dendrimer entrapped gold nanoparticles. Soft Matter. 2007;3(1):71-74.

19. Pan Y, Leifert A, Ruau D, et al. Gold nanoparticles of diameter $1.4 \mathrm{~nm}$ trigger necrosis by oxidative stress and mitochondrial damage. Small. 2009;5(18):2067-2076.

20. Kang B, Mackey MA, El-Sayed MA. Nuclear targeting of gold nanoparticles in cancer cells induces DNA damage, causing cytokinesis arrest and apoptosis. J Am Chem Soc. 2010;132(5):1517-1519.

21. Li JJ, Hartono D, Ong CN, Bay BH, Yung LY. Autophagy and oxidative stress associated with gold nanoparticles. Biomaterials. 2010;31(23): 5996-6003.

22. Minai L, Yeheskely-Hayon D, Yelin D. High levels of reactive oxygen species in gold nanoparticle-targeted cancer cells following femtosecond pulse irradiation. Sci Rep. 2013;3:2146.

23. Valko M, Leibfritz D, Moncol J, Cronin MT, Mazur M, Telser J. Free radicals and antioxidants in normal physiological functions and human disease. Int J Biochem Cell Biol. 2007;39(1):44-84.

24. Torres M. Mitogen-activated protein kinase pathways in redox signaling. Front Biosci. 2003;8:d369-d391.

25. Johnson GL, Lapadat R. Mitogen-activated protein kinase pathways mediated by ERK, JNK, and p38 protein kinases. Science. 2002;298(5600): 1911-1912. 
26. Hsin YH, Chen CF, Huang S, Shih TS, Lai PS, Chueh PJ. The apoptotic effect of nanosilver is mediated by a ROS- and JNK-dependent mechanism involving the mitochondrial pathway in NIH3T3 cells. Toxicol Lett. 2008;179(3):130-139.

27. Kroemer G, Galluzzi L, Brenner C. Mitochondrial membrane permeabilization in cell death. Physiol Rev. 2007;87(1):99-163.

28. Kluck RM, Bossy-Wetzel E, Green DR, Newmeyer DD. The release of cytochrome $\mathrm{c}$ from mitochondria: a primary site for Bcl-2 regulation of apoptosis. Science. 1997;275(5303):1132-1136.

29. Caruso F, Spasova M, Saigueirino-Maceira V, Liz-Marzan LM. Multilayer assemblies of silica-encapsulated gold nanoparticles on decomposable colloid templates. Adv Mater. 2001;13(14):1090.

30. Wang YS, Shao D, Zhang L, et al. Gold nanorods-silica Janus nanoparticles for theranostics. Appl Phys Lett. 2015;106(17).

31. Aziz MS, Suwanpayak N, Jalil MA, et al. Gold nanoparticle trapping and delivery for therapeutic applications. Int J Nanomedicine. 2012;7: 11-17.

32. Li Z, Barnes JC, Bosoy A, Stoddart JF, Zink JI. Mesoporous silica nanoparticles in biomedical applications. Chem Soc Rev. 2012;41(7): 2590-2605.

33. Choi E, Kwak M, Jang B, Piao Y. Highly monodisperse rattle-structured nanomaterials with gold nanorod core-mesoporous silica shell as drug delivery vehicles and nanoreactors. Nanoscale. 2013;5(1):151-154.

34. Li H, Tan LL, Jia P, et al. Near-infrared light-responsive supramolecular nanovalve based on mesoporous silica-coated gold nanorods. Chem Sci. 2014;5(7):2804-2808.

35. Ma N, Ma C, Li C, et al. Influence of nanoparticle shape, size, and surface functionalization on cellular uptake. J Nanosci Nanotechnol. 2013;13(10):6485-6498.
36. Akhtar MJ, Ahamed M, Kumar S, Khan MM, Ahmad J, Alrokayan SA. Zinc oxide nanoparticles selectively induce apoptosis in human cancer cells through reactive oxygen species. Int J Nanomedicine. 2012;7: 845-857.

37. Shao D, Li J, Guan F, et al. Selective inhibition of liver cancer growth realized by the intrinsic toxicity of a quantum dot-lipid complex. Int J Nanomedicine. 2014;9:5753-5769.

38. Soenen SJ, Manshian B, Montenegro JM, et al. Cytotoxic effects of gold nanoparticles: a multiparametric study. ACS Nano. 2012;6(7): 5767-5783.

39. Sharma V, Anderson D, Dhawan A. Zinc oxide nanoparticles induce oxidative DNA damage and ROS-triggered mitochondria mediated apoptosis in human liver cells (HepG2). Apoptosis. 2012;17(8):852-870.

40. Li Q, Liu G, Yuan H, et al. Mucin1 shifts Smad3 signaling from the tumor-suppressive pSmad3C/p21(WAF1) pathway to the oncogenic pSmad3L/c-Myc pathway by activating JNK in human hepatocellular carcinoma cells. Oncotarget. 2015;6(6):4253-4265.

41. Benhar M, Engelberg D, Levitzki A. ROS, stress-activated kinases and stress signaling in cancer. EMBO Rep. 2002;3(5):420-425.

42. Li Q, Liu G, Shao D, et al. Mucin1 mediates autocrine transforming growth factor beta signaling through activating the c-Jun N-terminal kinase/activator protein 1 pathway in human hepatocellular carcinoma cells. Int J Biochem Cell Biol. 2015;59:116-125.

43. Luo C, Li Y, Yang L, et al. Activation of Erk and p53 regulates copper oxide nanoparticle-induced cytotoxicity in keratinocytes and fibroblasts. Int J Nanomedicine. 2014;9:4763-4772.
International Journal of Nanomedicine

\section{Publish your work in this journal}

The International Journal of Nanomedicine is an international, peerreviewed journal focusing on the application of nanotechnology in diagnostics, therapeutics, and drug delivery systems throughout the biomedical field. This journal is indexed on PubMed Central, MedLine, CAS, SciSearch $®$, Current Contents ${ } /$ Clinical Medicine,

\section{Dovepress}

Journal Citation Reports/Science Edition, EMBase, Scopus and the Elsevier Bibliographic databases. The manuscript management system is completely online and includes a very quick and fair peer-review system, which is all easy to use. Visit http://www.dovepress.com/ testimonials.php to read real quotes from published authors. 